\title{
Adaptation behavior of skilled infant bouncers to different spring frequencies
}

\author{
Comportamento da adaptação das oscilações de bebés em diferentes \\ frequências de mola
}

\author{
Olinda Habib Perez ${ }^{1,2}$, Coren Walters-Stewart ${ }^{1,3}$, D.G. E Robertson ${ }^{1}$, Natalie Baddour ${ }^{3}$, \\ Heidi Sveistrup ${ }^{1,4^{*}}$
}

ARTIGO ORIGINAL | ORIGINALARTICLE

\begin{abstract}
Infants explore their environments through repetitive movements that are constrained or facilitated by the environmental context. In this study, we evaluated how skilled bouncers adapted to bouncing in systems with four different spring conditions (natural frequencies of 0.9, 1.15, 1.27 and $1.56 \mathrm{~Hz}$ ). Trunk kinematics and vertical ground reaction forces (VGRFs) were recorded from three pre-walking infants (mean age $10.6 \pm 0.9$ months). Bounce frequency, trunk displacement, peak VGRF, percent of time on the ground and time to peak force as a function of time on the ground were analyzed. In addition, infant bounce frequencies were compared to measured oscillations of an inert mass equivalent to each infant's mass. All infants bounced above the natural frequency of the spring system in all conditions suggesting that they did not behave solely like mass-spring systems. Infants produced asymmetrical VGRF loading patterns suggesting that a timing component, such as bounce frequency, was regulated. Skilled infants consistently increased their bounce frequency as their vertical trunk displacement decreased; however, the mode for regulating bounce frequency differed from infant to infant.
\end{abstract} Keywords: Motor skills; Infant; Biomechanics; Motor activity

RESUMO

Os bebés exploram o meio ambiente através de movimentos repetitivos que são constrangidos ou facilitados por esse mesmo meio. Neste estudo avaliámos como bebés adaptam as oscilações corporais em quatro condições diferentes (frequência natural de 0.9, 1.15, 1.27 e $1.56 \mathrm{~Hz}$ ). A frequência de oscilação, a cinemática do tronco e a componente vertical da força de reação ao solo (VFRS) foram registadas em bebés antes do domínio da marcha autónoma (idade média $10.6 \pm 0.9$ meses). Foram analisadas a frequência de oscilação, deslocamento do tronco, pico da VFRS, percentagem de tempo no solo e duração até ao pico da força em função do tempo. Além disso, as frequências de oscilação dos bebés foram comparadas com a de uma massa inerte de valor equivalente. Todos os bebés oscilaram acima da frequência natural do sistema mola em todas as condições, sugerindo que eles não se comportam apenas como um sistema mola-massa passivo. Os bebés produziram padrões de carga assimétricos para a VFRS, o que sugere que uma componente temporal, tal como a frequência de oscilação, foi regulada. Bebés consistentemente aumentaram a frequência de oscilação enquanto o deslocamento vertical do tronco diminuiu; contudo, o modo de regulação da frequência de oscilação difere de bebé para bebé. Palavras-chave: habilidades motoras, bebés, biomecânica, atividade motora

Manuscript received September $18^{\text {th }}, 2013$; Accepted June $3^{\text {rd }}, 2014$

${ }^{1}$ School of Human Kinetics, University of Ottawa

${ }^{2}$ Graduate Department of Rehabilitation Science, University of Toronto

${ }^{3}$ Department of Mechanical Engineering, University of Ottawa

${ }^{4}$ School of Rehabilitation Sciences, University of Ottawa

* Corresponding author. 200 Lees Avenue (A121), Ottawa Canada K1N 6N5;

E-mail: heidi.sveistrup@uottawa.ca 


\section{INTRODUCTION}

During development, infants explore their environment and incorporate multiple degrees of freedom to create repetitive movements that are constrained or facilitated by the environment (Angulo-Kinzler, Ulrich, \& Thelen, 2002; Chen, Fetters, Holt, \& Saltzman, 2002; Galloway \& Thelen, 2004; Goldfield, Kay, \& Warren, 1993; Heriza, 1991; Jensen, Thelen, Ulrich, Schneider, \& Zernicke, 1995; Jensen, Ulrich, Thelen, Schneider, \& Zernicke, 1994; Thelen, 1994). Infant bouncing is a highly complex repetitive closed-looped and taskspecific movement. Closed-looped movements occur throughout the ground contact phase. Commercially available infant bouncers (e.g., Jolly Jumper $\left.{ }^{\circledR}\right)$ provide trunk and body weight support but require the infant to generate a pushing force as the feet come in contact with the ground. Goldfield, Kay and Warren (1993) used a forced linear mass-spring model to explain infant bouncing and proposed that skilled bouncers used their legs as springs with peak bouncing frequency matching the resonant frequency of the spring. Matching the resonant frequency of a system suggests that a preferred movement behavior or an attractor state is achieved (Goldfield et al., 1993).

Goldfield et al. (1993) characterized infant bouncing throughout a six-week period by comparing an infant's peak bouncing frequency to the predicted resonant frequency of a singleand a double-spring model. Peak bouncing was achieved after an infant underwent an assembly phase, a process of self-organization, followed by a tuning phase through means of refining and adapting the movement. The researchers suggested that infants bounce close to the resonant frequency of the spring when they reached peak bouncing, defined as the bout with the greatest number of bounces. In fact, the peak bounce frequency was clearly higher than predicted by a single-spring model, which did not account for leg stiffness. Rather, infants bounced near the frequency predicted by the double-spring model where the infant's legs were modeled as the sum of two spring stiffnesses and behaved as a spring that matched the stiffness of the external spring. Similar bouncing frequencies were reported in subsequent studies (Foo, Goldfield, Kay, \& Warren, 2001; Vallis, 1998).

In a follow-up longitudinal study, preliminary findings from Foo et al. (2001) demonstrated that an infant bounced at different frequencies under multiple conditions suggesting that they could learn the dynamics of the task. In the baseline condition, the peak bounce period corresponded to a bounce frequency similar to the frequency predicted with a double-spring model, where the stiffnesses of the two springs are summed. In a second condition, spring stiffness was increased resulting in an increase in the natural frequency of the spring. In this condition, the infant consistently bounced at a frequency higher than that predicted by a single-spring model and lower than predicted by a double-spring model (Foo et al., 2001). In a third condition, the natural frequency of the spring was decreased by the addition of a mass and neither the single- nor double-spring models predicted the infant's behavior. Rather, the infant bounced at higher frequencies than predicted. These findings suggest that there must be an active contribution to bouncing behavior that is beyond having the legs behave like passive springs. Although Foo et al. (2001) identified that an infant bouncer that reached peak bouncing could bounce under different system constraints (i.e., additional mass and spring stiffness changes) their data did not provide evidence as to how infants modified their bounce frequency across conditions.

Goldfield et al., (1993) have proposed that infants learn the low-dimensional dynamics of a motor task - that is, they learn a function or set of rules that delimits all limb configurations rather than a specific pattern - and infants should quickly adapt to changes in the task conditions. An alternative is that infants learn all possible limb configurations in a highdimensional state space, but this would require learning numerous degrees of freedom of all 
joints. In bouncing, this would suggest that infants would not learn fixed leg stiffness or fixed timing of the forcing function (forcing frequency). Rather, successful bouncing, when the system's mass or spring stiffness are modified, would require the infants to adapt to the new parameters with different forcing frequencies or leg stiffness (Foo et al., 2001; Goldfield et al., 1993).

In this study, we measured trunk kinematics, along with vertical ground reaction forces (VGRFs) to quantitatively evaluate how skilled infant bouncers adapted their behaviors when placed in novel environments. This work provides empirical and quantitative information on short-term changes in bouncing behavior when infants are exposed to spring systems with four different natural frequencies. The current study focused on infants who were already considered to be "skilled" bouncers, which we defined as infants who could produce a minimum of three minutes of bouncing for all four of the test conditions. Additionally, this study is also the first to analyze kinematic and kinetic data from over 150 bounces for each skilled bouncer.

We hypothesized that if infants had learned the low-dimensional dynamics of the task (i.e., considered to be a skilled infant), that they would produce bouncing frequencies close to the natural frequency of the system across the different conditions demonstrating fast adaptability to the task. As the natural frequency of the spring system increases per condition, we hypothesized that infants would increase their bouncing frequency to keep up with the increments of the spring system. This behavior would in turn produce bounces of shorter duration, which requires less vertical displacement and lower vertical force. We proposed to evaluate the way in which the infants regulated their bouncing frequencies by analyzing VGRFs and vertical trunk displacement to characterize behavior across the various spring conditions. Preliminary results have been presented in abstract form (Habib Perez et al., 2010).

\section{METHODS}

\section{Participants}

Nine typically developing pre-walking infants between 5 and 12 months of age were recruited for participation. Infants were included if they were able to support their head, sit on their own and demonstrated bouncing behavior in a Jolly Jumper ${ }^{\circledR}$ bouncer or ExerSaucer ${ }^{\circledR}$ at home. Infants were excluded if they walked independently, did not produce a minimum of three minutes of bouncing behavior over the 15 minutes of continuous recording in the first condition of the study, or did not complete the four conditions. Of the nine infants, five were excluded from the study as they did not produce a minimum of three minutes of bouncing during in the first condition, while one infant completed three conditions but became ill and could not return to complete the fourth condition. Thus, this study analyzed data from three infants.

\section{Measures}

Three-dimensional kinematic data were recorded at $120 \mathrm{~Hz}$ (Vicon Nexus, Colorado; calibration error $<1.0 \mathrm{~mm}$ ) using $7 \mathrm{MX}$ cameras. Reflective markers identified the midsternum, the $8^{\text {th }}$ thoracic vertebrae and the top of the harness (one on each bar of the apparatus). VGRFs were recorded at $600 \mathrm{~Hz}$ with a $10 \mathrm{~N}$ threshold using two force platforms (Advanced Mechanical Technology, Inc. Model OR6-5).

A bounce was analyzed when it was a part of a series of six or more bounces, where the first bounce was removed to obtain bounces from series of continuous bouncing similar to other functional tasks such as steady-state walking (Breniere \& Do, 1986). The number of bounces analyzed in each condition for each infant was equal. Experimental data were processed using Visual3D (C-Motion, Inc.). Vertical positions of the $8^{\text {th }}$ thoracic vertebrae (T8) were extracted and movement trajectories were low-pass filtered ( $4^{\text {th }}$-order Butterworth, zerolag, and cutoff of $3 \mathrm{~Hz}$ ). Analog data from the two force platforms were low-pass filtered $\left(4^{\text {th }}\right.$ order Butterworth, zero-lag, and cutoff of 10 
$\mathrm{Hz}$ ), summed and used to determine when the infant was in contact with the ground.

Post-hoc processing was conducted with MATLAB2009b. A bounce cycle was defined from touch-down to subsequent touch-down using the VGRF data. The mean and variability of the bounce frequency (BF), T8 (trunk) vertical displacement, peak VGRF (pVGRF), percentage of time on the ground (\%Tground), and percentage of time to peak force as a function of time on the ground (\%TpVGRF) were analyzed.

\section{Instrumentation}

A spring system was designed to simulate a standard baby bouncer and could be modified with the addition of extension springs from commercial baby bouncers and weights to approximate four spring frequency conditions $(0.9,1.15,1.27$ and $1.56 \mathrm{~Hz})$. The spring system was suspended from the ceiling with the use of a chain over two floor mounted force platforms.

\section{Experimental Procedures}

Inert Mass (IM) Experiment

Pilot experiments were conducted to determine the number of springs and additional masses that would be needed for the spring system to reach the four predetermined frequencies for each infant. For each of the four spring conditions, a mass equivalent to the infant's mass was suspended from the spring system. The number of springs (up to three) and the amount of additional weight on the bar (up to $6 \mathrm{~kg}$ ) were manipulated (Fig. 1) and the spring system was set into an oscillating motion. The natural oscillation frequency of the IM was computed from motion of passive reflective markers attached to the mass.

\section{Infant Experiment}

The University of Ottawa Research Ethics Board approved this protocol and parents or guardians provided informed consent for the infant to participate. Each infant participated in two testing sessions, two conditions per session, within a 7-day period. At each session, the infant was weighed and placed in the spring system with the knees slightly bent and the balls of the feet touching the force platforms (Vallis, 1998). Infants were given a few minutes to familiarize themselves to the $0.9 \mathrm{~Hz}$ spring condition (Co1), analogous to frequencies from their bouncer at home. In the first session bouncing was recorded for a period of up to 15 minutes in Co1 followed by $\mathrm{Co} 2$ $(1.15 \mathrm{~Hz})$. The second session placed infants in Co3 $(1.27 \mathrm{~Hz})$ and Co4 $(1.56 \mathrm{~Hz})$. Pilot data demonstrated that the conditions used appeared to be increasingly difficult (from $\mathrm{Col}$ to Co4) as fewer infants were able to bounce at the higher spring frequencies. Thus, conditions were not randomized to allow the infants sufficient time to accommodate to one frequency prior to moving to the next more difficult condition.

\section{Statistical Analyses}

Statistical analyses were performed using IBM SPSS 20.0. Independent sample $t$-tests were conducted for each infant to determine whether significant differences existed between the infant's bounce frequency and the oscillation frequency of the IM in each of the four conditions. Individual bounce cycles were assumed to be independent. Independent $3 \times 4$ (Infant $\times$ Condition) one-between-one-within analyses of variance (ANOVAs) were conducted on all dependent variables. When homogeneity of variance or sphericity assumptions were not met, Greenhouse-Geisser (GG) corrections were applied and more conservative alphas $(\alpha=0.01)$ were used for Infant, Condition, and Interaction effects. Follow-up analyses of significant Infant, Condition, and Interaction effects $(\alpha=0.01)$, were conducted: oneway ANOVAs to identify significant differences between infants for each condition $(\alpha=0.05)$; repeated-measures (RM) ANOVAs determined whether significant differences existed within infants across the four conditions $(\alpha=0.05)$. When homogeneity of variance was not assumed, Welch's values are reported. Omega 
squared $\left(\omega^{2}\right)$ was calculated for effect size to maintain consistency between comparisons rather than reporting eta squared $\left(\eta^{2}\right)$ for oneway ANOVAs. For RM ANOVAs, partial $\eta^{2}$ were reported despite using GG adjusted values when homogeneity of variance was not

A

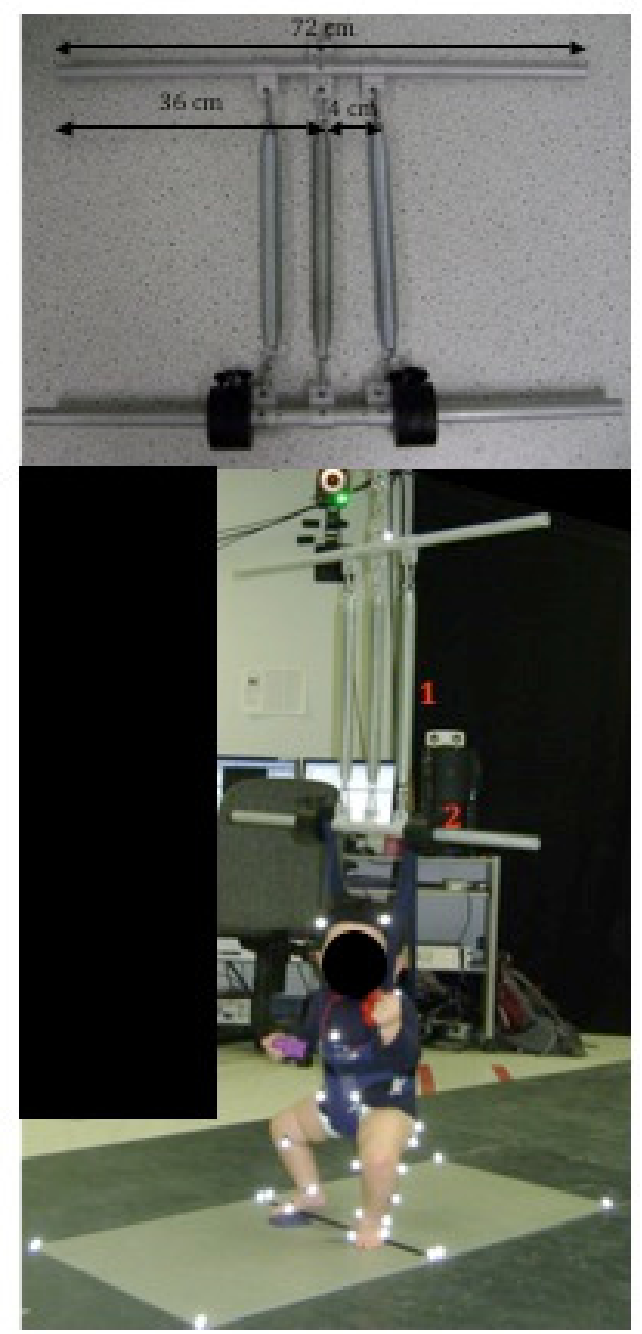

assumed. Pair-wise comparisons with Bonferroni corrected $\mathrm{p}$-values were used to identify significant differences across all infants $(\alpha=$ $0.017)$ and conditions $(\alpha=0.008)$.

B
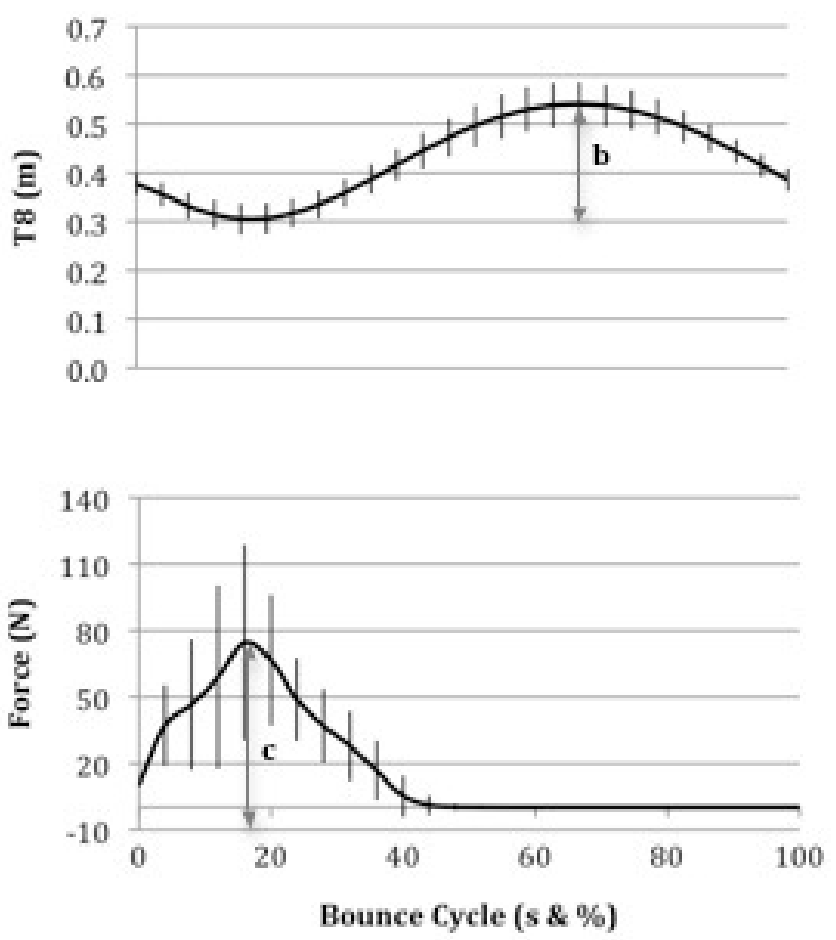

Figure 1. A - Spring system apparatus with three springs (1) and $3 \mathrm{~kg}$ disc weights (2). Infant instrumented with full marker set. 1B - Experimental vertical ground reaction force (VGRF) and T8 displacement data demonstrating the five (arrows) dependent variables in the study: a) bounce period (used to compute bounce frequency); b) T8 displacement; c) peak force; d) percent of time on the ground; and e) percent of time to peak force. 
30 | O Habib Perez, C Walters-Stewart, DGE Robertson, N Baddour, H Sveistrup

Table 1

Inert Mass (IM) frequency of oscillation values and mean and standard deviation for each infant for all dependent variables. BF - bounce frequency; $p V G R F-$ peak VGRF; \%Tground - percent of time on the ground relative to bounce time; \%TpVGRF - percent of time to peak force relative to time on the ground; and cV - coefficient of variation

\begin{tabular}{|c|c|c|c|c|c|c|c|c|c|c|c|c|}
\hline \multirow{2}{*}{$\begin{array}{c}\text { Infant } \\
\text { Condition }\end{array}$} & \multicolumn{4}{|c|}{ Infant 1} & \multicolumn{4}{|c|}{ Infant 2} & \multicolumn{4}{|c|}{ Infant 3} \\
\hline & 1 & 2 & 3 & 4 & 1 & 2 & 3 & 4 & 1 & 2 & 3 & 4 \\
\hline No. of Bounces & 165 & 165 & 165 & 165 & 427 & 427 & 427 & 427 & 364 & 364 & 364 & 364 \\
\hline IM Frequency $(\mathrm{Hz})$ & 0.87 & 1.16 & 1.27 & 1.55 & 0.91 & 1.14 & 1.28 & 1.57 & 0.90 & 1.14 & 1.26 & 1.56 \\
\hline $\mathrm{BF}(\mathrm{Hz})$ & $1.14 \pm .08$ & $1.39 \pm .23$ & $1.52 \pm .17$ & $1.83 \pm .22$ & $1.05 \pm .07$ & $1.29 \pm .13$ & $1.42 \pm .13$ & $1.75 \pm .19$ & $1.07 \pm .05$ & $1.26 \pm .13$ & $1.42 \pm .15$ & $1.76 \pm .18$ \\
\hline $\mathrm{BF} \mathrm{cV}$ & 0.07 & 0.17 & 0.11 & 0.12 & 0.07 & 0.10 & 0.09 & 0.11 & 0.05 & 0.10 & 0.11 & 0.10 \\
\hline $\begin{array}{l}\text { T8 Vertical Dis- } \\
\text { placement }(\mathrm{m})\end{array}$ & $0.24 \pm .07$ & $0.18 \pm .07$ & $0.14 \pm .05$ & $0.11 \pm .02$ & $0.26 \pm .03$ & $0.19 \pm .04$ & $0.14 \pm .03$ & $0.10 \pm .01$ & $0.39 \pm .08$ & $0.26 \pm .04$ & $0.17 \pm .04$ & $0.11 \pm .02$ \\
\hline pVGRF (N) & $84.1 \pm 40.7$ & $56.1 \pm 22.5$ & $42.0 \pm 19.5$ & $33.3 \pm 12.3$ & $31.4 \pm 11.1$ & $29.0 \pm 10.1$ & $26.5 \pm 8.9$ & $23.1 \pm 7.5$ & $76.4 \pm 27.6$ & $33.2 \pm 11.0$ & $29.1 \pm 13.5$ & $29.5 \pm 18.2$ \\
\hline pVGRF cv & 0.48 & 0.40 & 0.46 & 0.37 & 0.35 & 0.35 & 0.34 & 0.32 & 0.36 & 0.33 & 0.46 & 0.62 \\
\hline $\begin{array}{l}\text { \%Tground } \\
\text { (\%bounce) }\end{array}$ & $36.6 \pm 5.5$ & $34.6 \pm 5.8$ & $40.1 \pm 9.4$ & $39.4 \pm 11.1$ & $26.4 \pm 8.7$ & $23.9 \pm 9.2$ & $27.1 \pm 9.7$ & $34.7 \pm 11.5$ & $29.8 \pm 4.2$ & $34.3 \pm 8.4$ & $26.7 \pm 9.2$ & $29.2 \pm 10.8$ \\
\hline $\begin{array}{l}\text { \%TpVGRF } \\
\text { (\%Tground) }\end{array}$ & $43.6 \pm 12.3$ & $42.6 \pm 19.4$ & $44.0 \pm 18.2$ & $42.7 \pm 20.9$ & $34.3 \pm 22.2$ & $34.5 \pm 23.0$ & $29.9 \pm 22.7$ & $50.3 \pm 20.4$ & $44.6 \pm 10.4$ & $35.8 \pm 26.1$ & $42.5 \pm 23.2$ & $48.1 \pm 18.4$ \\
\hline
\end{tabular}

Table 2

Summary of $3 \times 4$ one-between-one-within ANOVA statistical outcomes

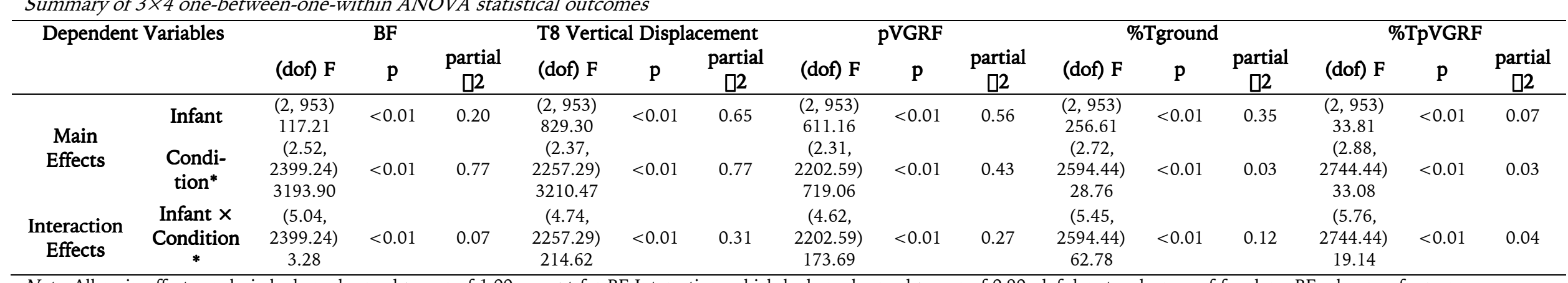

Note: All main effects analysis had an observed power of 1.00, except for BF Interaction, which had an observed power of 0.90. dof denotes degrees of freedom. BF - bounce frequency; pVGRF - peak vertical ground reaction force; \%Tground - percentage of time of the ground; \%TpVGRF - percentage of time to peak force as a function of time on the ground. * denotes Greenhouse-Geisser adjusted $F$ ratio values 
Table 3

Summary of main effects of Infant (One-way ANOVA) and Condition (Repeated Measures ANOVA)

\begin{tabular}{|c|c|c|c|c|c|c|c|c|c|c|c|}
\hline \multirow[b]{2}{*}{$\begin{array}{l}\text { Main } \\
\text { Effects }\end{array}$} & \multirow[t]{2}{*}{$\begin{array}{l}\text { Dependent } \\
\text { Variables }\end{array}$} & \multicolumn{2}{|l|}{ BF } & \multicolumn{2}{|c|}{$\begin{array}{c}\text { T8 Vertical Displace- } \\
\text { ment }\end{array}$} & \multicolumn{2}{|c|}{ pVGRF } & \multicolumn{2}{|c|}{ \%Tground } & \multicolumn{2}{|c|}{ \%TpVGRF } \\
\hline & & (dof) $\mathrm{F}$ & $\square 2$ & (dof) $F$ & $\square 2$ & (dof) F & $\square 2$ & (dof) F & $\square 2$ & (dof) $\mathrm{F}$ & $\square 2$ \\
\hline \multirow[t]{4}{*}{ Infant } & Col & $\begin{array}{c}(2,417.28) \\
100.99 * \mathrm{a}\end{array}$ & 0.02 & $\begin{array}{l}(2,365.94) \\
462.82 * a\end{array}$ & 0.55 & $\begin{array}{l}(2,333.85) \\
531.84^{*} \mathrm{a}\end{array}$ & 0.47 & $\begin{array}{c}(2,437.40) \\
154.44^{*} \mathrm{a}\end{array}$ & 0.22 & $\begin{array}{c}(2,455.17) \\
37.72 * \mathrm{a}\end{array}$ & 0.08 \\
\hline & $\mathrm{Co} 2$ & $\begin{array}{c}(2,389.95) \\
25.36^{*} \mathrm{a}\end{array}$ & 0.08 & $\begin{array}{l}2,389.17) \\
392.34^{*} \mathrm{a}\end{array}$ & 0.41 & $\begin{array}{c}(2,379.01) \\
115.25^{*} \mathrm{a}\end{array}$ & 0.34 & $\begin{array}{c}(2,530.63) \\
185.84^{*} \mathrm{a}\end{array}$ & 0.28 & $\begin{array}{l}(2,483.99) \\
9.66 * a\end{array}$ & 0.01 \\
\hline & $\mathrm{Co} 3$ & $\begin{array}{l}(2,414.69) \\
24.84^{*} \mathrm{~b}\end{array}$ & 0.06 & $\begin{array}{c}2,396.83) \\
64.09 * \mathrm{a}\end{array}$ & 0.12 & $\begin{array}{c}(2,370.17) \\
49.59 * \mathrm{a}\end{array}$ & 0.15 & $\begin{array}{l}(2,953) \\
132.63 \mathrm{a}\end{array}$ & 0.22 & $\begin{array}{l}(2,488.42) \\
42.87^{*} \mathrm{a}\end{array}$ & 0.08 \\
\hline & $\mathrm{Co} 4$ & $\begin{array}{c}(2,953) \\
10.45 \mathrm{a}\end{array}$ & 0.02 & $\begin{array}{l}(2,383.61) \\
28.31^{*} \mathrm{a}\end{array}$ & 0.05 & $\begin{array}{c}(2,375.19) \\
62.18^{*} \mathrm{a}\end{array}$ & 0.08 & $\begin{array}{c}(2,953) 52.29 \\
\mathrm{a}\end{array}$ & 0.10 & $\begin{array}{c}(2,439.37) \\
7.82 * \mathrm{a}\end{array}$ & 0.02 \\
\hline $\begin{array}{l}\text { Main } \\
\text { Effects }\end{array}$ & & (dof) $\mathrm{F}$ & $\begin{array}{l}\text { partial } \\
\square 2\end{array}$ & (dof) F & $\begin{array}{l}\text { partial } \\
\square 2\end{array}$ & (dof) F & $\begin{array}{l}\text { partial } \\
\square 2\end{array}$ & (dof) F & $\begin{array}{l}\text { partial } \\
\square 2\end{array}$ & (dof) $\mathrm{F}$ & $\begin{array}{l}\text { partial } \\
\square 2\end{array}$ \\
\hline \multirow[t]{3}{*}{ Condition } & I1 & $\begin{array}{c}(2.5,409.94) \\
380.03 \dagger a\end{array}$ & 0.70 & $\begin{array}{c}(2.64,432.19) \\
211.23 \dagger \mathrm{a}\end{array}$ & 0.56 & $\begin{array}{c}(1.96,321.00) \\
122.90 \dagger a\end{array}$ & 0.43 & $\begin{array}{c}(2.46,403.93) \\
15.17 \dagger \mathrm{a}\end{array}$ & 0.09 & $\begin{array}{c}(2.76,452.87) \\
0.229 \dagger c\end{array}$ & 0.001 \\
\hline & $\mathrm{I} 2$ & $\begin{array}{c}(2.44 \\
1037.85) \\
1987.50 \dagger a\end{array}$ & 0.82 & $\begin{array}{c}(2.63 \\
1118.82) \\
2313.33 \dagger \mathrm{a}\end{array}$ & 0.84 & $\begin{array}{c}(2.92 \\
1243.57) \\
64.06 \dagger \mathrm{a}\end{array}$ & 0.13 & $\begin{array}{c}(2.87 \\
1222.82) \\
100.52 \dagger a\end{array}$ & 0.19 & $\begin{array}{c}(2.94 \\
1250.18) \\
71.01 \dagger a\end{array}$ & 0.14 \\
\hline & I3 & $\begin{array}{c}(2.42,876.64) \\
1710.85 \dagger a\end{array}$ & 0.83 & $\begin{array}{c}(1.95,706.07) \\
2322.49 \dagger \mathrm{a}\end{array}$ & 0.87 & $\begin{array}{c}(2.29,829.49) \\
560.53 \dagger a\end{array}$ & 0.61 & $\begin{array}{c}(2.49,903.17) \\
49.94 \dagger a\end{array}$ & 0.12 & $\begin{array}{c}(2.68,972.39) \\
23.79 \dagger a\end{array}$ & 0.06 \\
\hline
\end{tabular}

Note: dof denotes degree of freedom. BF - bounce frequency; pVGRF - peak vertical ground reaction force; \%Tground - percentage of time of the ground; \%TpVGRF - percentage of time to peak force as a function of time on the ground. " denotes Welch and ${ }^{\dagger}$ denotes GG adjust F ratio value. ${ }^{\mathrm{a}} \mathrm{p}<0.0005 ;{ }^{\mathrm{b}} \mathrm{p} \leq 0.05{ }^{\mathrm{c}} \mathrm{p} \geq 0.05$ 


\section{RESULTS}

Data for four conditions were obtained from three typically developing infants (3 males) aged 9.4 to 11.5 months (mean $=10.6$, $\mathrm{SD}=0.91)$. The average masses and supine length of these infants were $10.4( \pm 0.6) \mathrm{kg}$ and $73.6( \pm 2.4) \mathrm{cm}$, respectively. There were no significant differences between the average masses $(9.7 \pm 1.7 \mathrm{~kg}$ ) and age (of first testing session; $9.2 \pm 1.6$ months) of excluded infants $(\mathrm{p}>0.05)$. The three infants (I1, I2 and I3) spent 150, 210 and 315 minutes per week in a commercial bouncer (e.g., Jolly Jumper ${ }^{\circledR}$ ) in their home, respectively. Bounce analysis in each condition for I1, I2 and I3 included 165, 427 and 364 bounces, respectively.

Summary data are presented in Table 1 . Significant interaction effects (Infant $\times$ Condition) and significant main effects (Infant, Condition) were found for all dependent variables (Table 2). Statistical results of one-way ANOVAs and RM ANOVAs can be found in Table 3 , and pair-wise comparisons for each dependent variable are reported below.

\section{Bounce Frequency}

All infants bounced at significantly higher bounce frequencies (BF) in each condition than the natural frequency of the system (IM) (all comparisons $\mathrm{p}<0.0005$ ). There was a significant effect of Infant on BF in all conditions. Although I2 and I3 bounced at significantly lower frequencies than I1 at each condition $(\mathrm{p} \leq 0.014)$, the BF increased as the natural frequency of the system increased for all infants $(p<0.0005$; see Fig. 2). Noticeably, the difference between the infant's bounce frequency and the natural frequency was approximately constant for each infant (I1: $0.26 \mathrm{~Hz}$; I2: $0.15 \mathrm{~Hz}$; I3: $0.16 \mathrm{~Hz}$ ). In all infants, bounce frequency variability increased as spring frequency increased (Table 1).

\section{Trunk Displacement}

T8 vertical displacement varied significantly across infants in all conditions except for I1 and $\mathrm{I} 2$ in $\mathrm{Co} 2$ and $\mathrm{Co} 3$, and $\mathrm{I} 1$ and $\mathrm{I} 3$ in $\mathrm{Co} 4$ $(\mathrm{p}<0.0005$; see Fig. 3a) with T8 vertical displacement decreasing significantly as spring frequency increased in all infants (all comparisons $\mathrm{p}<0.0005)$. The variability of $\mathrm{T} 8$ displacement within condition was low and generally decreased as spring frequency increased.

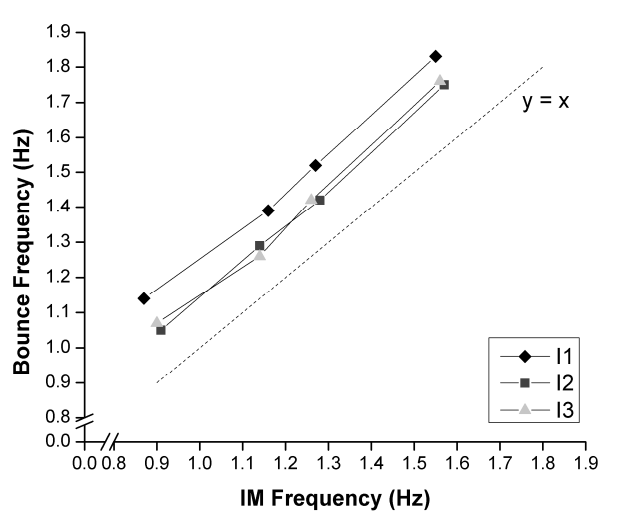

Figure 2. Frequency at which infants bounced (BF) versus the natural frequency of inert mass (IM) for all infants 1 to 3 (I1-I3). Linear function of $y=x$ is displayed in dotted line

\section{Peak Force}

All comparisons of pVGRF between infants at each frequency condition were significantly different ( $\mathrm{p} \leq 0.016)$, with I1 consistently generating the highest pVGRFs (Fig. 3b). Two different loading patterns were characterized by i) a significant decrease in pVGRF across the four conditions seen in I1 $(p<0.0005)$ and I2 $(\mathrm{p} \leq 0.002)$ or ii) a significant decrease in pVGRF from Col to Co2 with no significant additional change seen in I3 $(\mathrm{p}<0.0005)$. The relationship between $\mathrm{T} 8$ vertical displacement and peak force is shown in Fig. 4.

\section{Percent of time on the ground}

The \%Tground varied significantly by infant for Co1 $(\mathrm{p}<0.0005)$ and $\mathrm{Co} 4(\mathrm{p}<0.0005)$ (Fig. $3 c)$. For Co2, I1 and I3 spent significantly longer time on the ground than I2 $(\mathrm{p}<0.0005)$ while in Co3, I1 spent significantly longer time on the ground than I2 $(\mathrm{p}<0.0005)$ and I3 $(\mathrm{p}<0.0005)$. Specifically, for I1 and I3 the \%Tground gradually decreased across conditions (all comparisons $\mathrm{p} \leq 0.007$ except Co1- 
Co4 and Co3-Co4). Except for Co1 and Co3, the \%Tground was significantly different across all conditions for $\mathrm{I} 2(\mathrm{p}<0.0005)$ with a significant decrease from $\mathrm{Co} 1$ to $\mathrm{Co} 2$ followed by a gradual increase in $\mathrm{Co} 3$ and Co4. The variability of the \%Tground increased with spring frequency for each infant.

\section{Time to peak force as a function of time on the ground}

Although significances were found across most infant $(\mathrm{p} \leq 0.011)$ and conditions comparisons for I2 and I3 $(\mathrm{p} \leq 0.03)$, there were no patterns identified in the \%TPVGRF in the loading phase amongst infants (Fig. 3d).
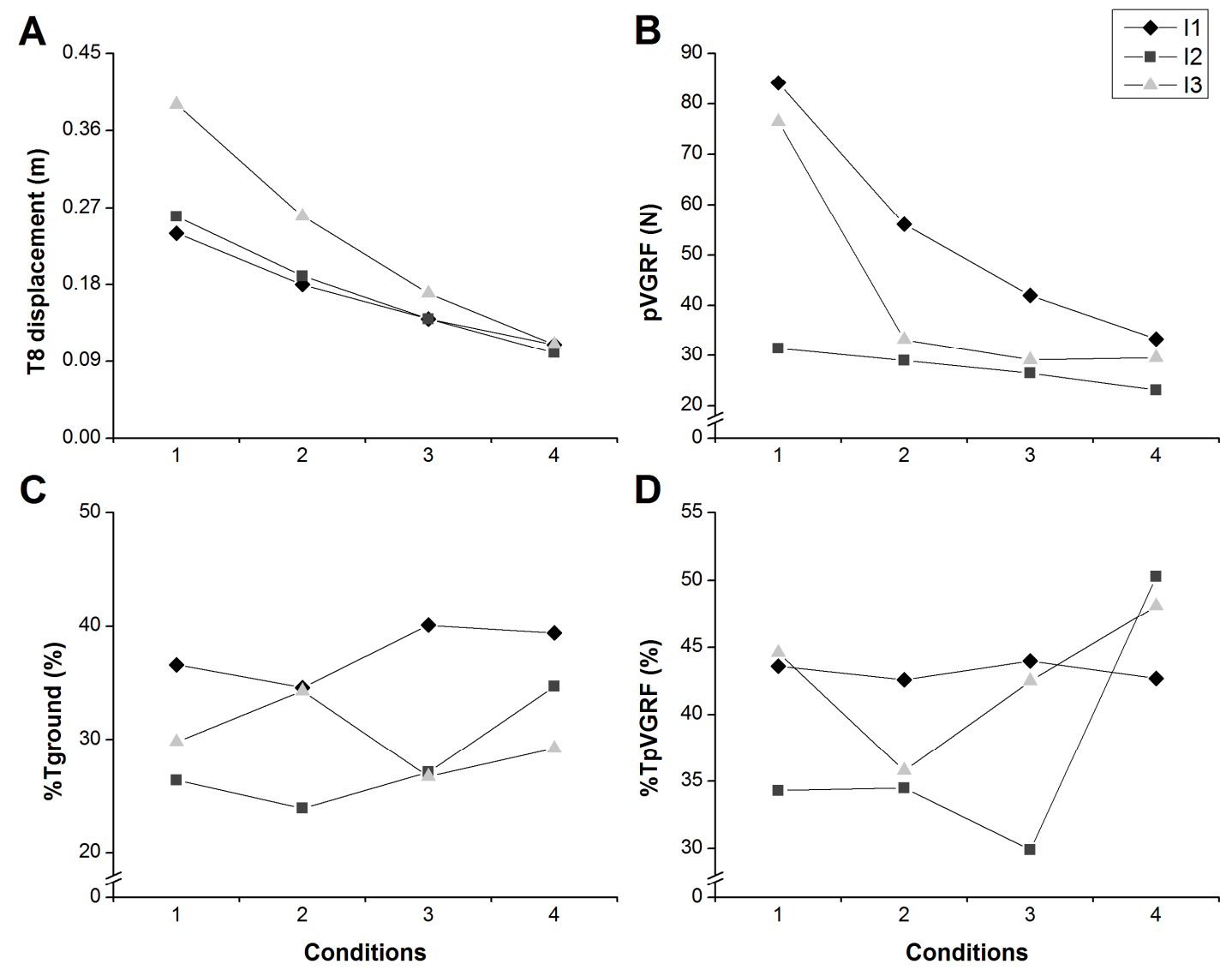

Figure 3. T8 vertical displacement (A), peak vertical ground reaction force (pVGRF) (B), percentage of time on the ground (\%Tground) (C) and percentage of time to peak force (\%TpVGRF) as a function of time on the ground (D) for conditions 1 to 4 (Co1-Co4) for all infants 


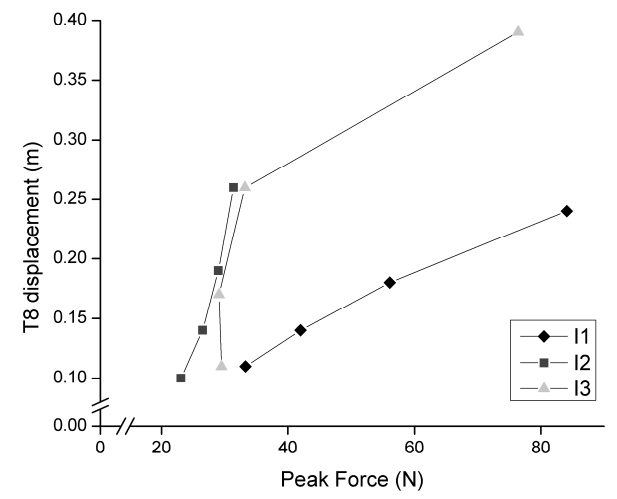

Figure 4. T8 vertical displacement and peak force relationship for all infants across all conditions

\section{DISCUSSION}

The objective of this study was to investigate whether and how skilled infant bouncers adapt their bouncing behavior to different spring systems. All infants adapted to the changes in the spring system by bouncing at a constant offset $(\sim+0.2 \mathrm{~Hz})$ above the natural frequency of the spring system in all conditions (see Fig. 2). The offset suggests that the infants actively contributed to the bouncing activity most likely by changes in the VGRFs they generated. This demonstrates that these infants did not solely behave as passive massspring systems. Additionally, as infants were not restricted for bounce height, infants bounced above the natural frequency of the spring system to regulate their own bounce frequency. The data demonstrated that I3 bounced at higher amplitudes than the other infants, but since all infants bounced from the same spring system this suggests that the heights reached by I1 and I 2 were not restricted by the mechanical properties of the spring system.

Bounce frequency variability increased as the frequency of the spring system increased from $0.9 \mathrm{~Hz}$ to $1.56 \mathrm{~Hz}$ for the three infants. Since these skilled infants had already learned bouncing behavior (i.e. the low-dimensional dynamics of the task) with a commercial system, we hypothesized that they would begin bouncing in a very stable attractor state that would be characterized by movement patterns with low variability (Goldfield et al., 1993). As the infants were exposed to spring system with novel natural frequencies, their behavior became less stable as reflected by the increase in bounce frequency variability for all infants across conditions. This suggests that the infants underwent the process of parameter tuning to refine and adapt their movement to a novel environment (Goldfield et al., 1993). Similar increases of variability in novel situations have been noted in unimanual and bimanual wrist oscillations (Kay, Kelso, Saltzman, \& Schöner, 1987).

Goldfield et al. (1993) found that when infants learned the low-dimensional dynamics of bouncing, bounce amplitude significantly increased with a non-significant increase of $50 \%$ in variability as infants reached peak bouncing. The researchers suggested that changes in bounce amplitude at peak bouncing as a result of minor variations in the forcing frequency, were no different to the greater variations of the forcing frequency at tuning. We found that as the natural frequency of the spring system increased, both the amplitude and variability of T8 vertical displacement decreased for all infants. Findings from wrist oscillatory movements and limb coordination dynamics at various frequencies demonstrated that increasing oscillations were achieved by decreased movement amplitude with variability increasing (Jeka \& Kelso, 1995; Kay et al., 1987). In these studies, producing increasing movement frequencies was achieved by decreasing movement amplitudes with discrete and continuous auditory cued frequency changes. After learning the dynamics of the bouncing task, tuning of parameters in $\mathrm{Co} 2$ through Co4 may suggest that changes in forcing frequency contributed to the decrease in $\mathrm{T} 8$ displacement variability. The findings suggest that the natural frequency of the spring system affects the bouncing frequency similarly to the auditory driven oscillatory behavior in wrist and limb movements. This notion is supported by the infants' linear function as displayed in Fig. 2. 
In all infants, as bounce frequency increased the pVGRFs and pVGRF variability decreased. This is reflected in the pVGRF coefficient of variation $(\mathrm{CV})$ in $\mathrm{I} 1$ and $\mathrm{I} 2$ with pVGRF $\mathrm{CV}$ decreasing from $\mathrm{Co} 1$ to Co4. Although a decrease was seen in $\mathrm{I} 3$ from $\mathrm{Co} 1$ to $\mathrm{Co} 2$ no further decreases in pVGRF $C_{V}$ were found in $\mathrm{Co} 3$ and Co4. Peak force has not yet been reported or examined in the context of infant bouncing, but one can turn to jumping studies to find possible explanations. Similar to infant bouncing, jumping requires the legs to flex and extend; however, jumping requires the propulsion of the whole body from a surface with either one or both feet and the ability to land and balance on two feet when coming in contact with the ground. In earlier studies, the effects of different heights on impact forces during landings were investigated in drop jumps on normal surfaces (Dufek \& Bates, 1990) and sprung surfaces (Arampatzis, Brüggemann, \& Klapsing, 2001). Infant bouncing demonstrated a similar curvilinear jumping relationship (Arampatzis et al., 2001; Dufek \& Bates, 1990) between the T8 vertical displacement and the pVGRFs, as pVGRFs decreased in $\mathrm{Co} 2$ then stabilized at higher frequencies. Therefore, the curvilinear relationship by I3 between the T8 vertical displacement and the VGRFs (displayed in Fig. 4) illustrates that infant bouncing and jumping may share similar properties, where infant bouncing behavior is not a replicated model of a passive mass-spring system. The relatively linear relationship by I1 and 12 suggests that the range of frequencies used in this study did not drive these infants to demonstrate curvilinear behavior as seen in jumping. An additional condition at a higher frequency may have elicited such curvilinear behaviors in these infants.

Additionally, adult jumping demonstrated asynchronous force trajectories (Parkhouse \& Ewins, 2006) and was modeled to incorporate phases lags that consider jump-to-jump timing and amplitude variations (Racic \& Pavic, 2010; Sim, Blakeborough, Williams, \& Parkhouse,
2008). When a jumper was asynchronous to an auditory beat, phase deviations between jumps were corrected by timing adjustments from the previous jump asynchrony in an effort to maintain synchronicity with the beat (Sim et al., 2008). In the current study, all infants produced decreasing VGRFs and spent less time on the ground than in the air as spring frequency increased. We also noticed that timing asymmetries corresponded to steeper force loading than unloading rates, as the percentage of time to peak force was less than $50 \%$ for all infants in most conditions. Asymmetry has been associated with reducing timing errors (Balasubramaniam, Wing, \& Daffertshofer, 2004; Wing, 2002), thus the asymmetry found in the \%TpVGRFs suggests that it relates to attempts to correct timing accuracy. With respect to tasks and motor goals, Balasubramanium et al. (2004) proposed that asymmetry in movement trajectories were used to reduce timing errors. The greater asymmetry found in finger trajectory, the closer the finger was to synchronous timing in such a way that when the finger arrived early and produced large asynchrony, the finger would compensate by a longer return phase that would correct for the asynchrony (Balasubramaniam et al., 2004). The use of asymmetrical trajectories to regulate timing can be applied to infant bouncing as skilled infants may be trying to optimize a timing component, the bounce frequency. The asymmetrical loading pattern visible in the \%TpVGRFs produced by the infants may reflect how infants regulate and correct this timing component.

The present study illustrates that skilled infants respond to the spring system changes by increasing their bounce frequency, but their methods of regulating (i.e., mode) bounce frequency differed from infant to infant. Vallis (1998) demonstrated that infants can produce two types of bouncing behavior where infants bounce at one-and-a-half or two times the natural frequency of the mass-spring system. These two behaviors were proposed to reflect different attractors states that might be identi- 
fied in different phase planes patterns (Vallis, 1998). Findings from Angulo-Kinzler, Ulrich and Thelen (2002) in an infant kicking task showed that 3-month-old infants were able to move a mobile by reaching a desired angular threshold of knee flexion and extension in two different modes. In the current study, I1-I3 bounced at similar increasing frequencies; however, the percentage of time each infant was in contact with the ground varied and the method of loading and unloading their forces (i.e., error correction) were infant dependent.

This study investigated how three skilled infant bouncers adapted their bouncing behavior to different spring systems. Although a small number of the infants tested were able to complete all experimental conditions, the infants included were able to generate a large number of bounces with low variability at all the natural frequencies tested. Moreover, the three infants produced similar bounce frequency patterns across conditions suggesting that the bouncing patterns used may be generalizable to these specific frequencies. Interestingly, the three infants who completed the trials were all male. There is some evidence that the average male infant moves more than the average female infant (Campbell \& Eaton, 1999) and this difference in motor activity level may have influenced the final subject sample. Sex differences were not a primary question in the study and will need to be further explored. Future studies are recommended to explore various bouncing skill levels by a measure of how often an infant can bounce in one condition, as this would increase the sample size.

\section{CONCLUSIONS}

The present study quantitatively analyzed the adaptation behaviors of three skilled infant bouncers to the changing spring system conditions. Our data demonstrated that infants do not bounce like a passive mass-spring system since they always bounced above the natural frequency of the spring system using different modes of bouncing to regulate bounce frequency. As all the infants were able to adapt to the changes of the spring system, the study corroborates Goldfield's et al. (1993) prediction that once infants have learned the lowdimensional dynamics of bouncing, they are able to adapt to the task rapidly. We suggest that infants adapted to new parameters of the spring system by changing their forcing frequency and leg stiffness that contributed to the varying VGRFs per jump as contact was made with the ground. As the infants' bounce frequency increased, the vertical displacement of the trunk and the vertical ground reaction forces decreased. Increased bounce frequency variability suggests that infants completed a process of parameter tuning to refine and adapt the movement in novel environments. Additionally, the study demonstrated that infants were regulating a timing component (bounce frequency) when they came in contact with the ground. The loading pattern of asymmetrical ground reaction forces suggests that infants correct for timing errors as a method to regulate the bounce frequency.

\begin{abstract}
Acknowledgments:
We thank the parents and infants for their participation and H. Purnell., C. Pelletier-Time, A. Kennedy and S. Becker for their help during all testing sessions. We would also like to thank A. MineaultGuitard, who assisted with the data processing and Dr. Tanya Forneris for assisting with the statistical analysis. The Faculty of Health Sciences at the University of Ottawa supported this project. Through the writing of this manuscript, the NSERC CARE award supported the first author.
\end{abstract}

\section{Conflicts of Interest:}

Nothing to declare.

\section{Funding:}

Faculty of Healthy Science, University of Ottawa; NSERC CARE supported the first author throughout the writing of the manuscript 


\section{REFERENCES}

Angulo-Kinzler, R. M., Ulrich, B., \& Thelen, E. (2002). Three-month-old infants can select specific leg motor solutions. Motor Control, 6(1), 52-68.

Arampatzis, A., Brüggemann, G. P., \& Klapsing, G. M. (2001). Leg stiffness and mechanical energetic processes during jumping on a sprung surface. Medicine and Science in Sports and Exercise, 33(6), 923-931.

Balasubramaniam, R., Wing, A. M., \& Daffertshofer, A. (2004). Keeping with the beat: movement trajectories contribute to movement timing. Experimental Brain Research, 159(1), 129134. http://doi.org/10.1007/s00221-0042066-z

Breniere, Y., \& Do, M. C. (1986). When and how does steady state gait movement induced from upright posture begin? Journal of Biomechanics, 19(12), 1035-1040. http://doi.org/10.1016/0021-9290(86)90120$\mathrm{X}$

Campbell, D. W., \& Eaton, W. O. (1999). Sex differences in the activity level of infants1. Infant and Child Development, 8(1), 1-17. http://doi.org/10.1002/(SICI) 15227219(199903)8:1<1::AID-ICD186>3.0.CO;2$\mathrm{O}$

Chen, Y.-P., Fetters, L., Holt, K. G., \& Saltzman, E. (2002). Making the mobile move: Constraining task and environment. Infant Behavior and Development, 25(2), 195-220. http://doi.org/10.1016/S01636383(02)00121-2

Dufek, J. S., \& Bates, B. T. (1990). The evaluation and prediction of impact forces during landings. Medicine and Science in Sports and Exercise, 22(3), 370-377.

Ewins, D. J., \& Parkhouse, J. G. (2006). Crowdinduced rhythmic loading. Proceedings of the ICE - Structures and Buildings, 159(5), 247259. http://doi.org/10.1680/stbu.2006.159.5.247

Foo, P., Goldfield, E. C., Kay, B. A., \& Warren, W. H. (2001). Infant bouncing: The assembly, tuning, and transfer of action systems (Vol. 6, p. 5377). Apresentado na 9th International Congress on Research in Physical Activity and Sport, Valence, France.

Galloway, J. C., \& Thelen, E. (2004). Feet first: Object exploration in young infants. Infant Behavior \& Development, 27(1), 107-112. http://doi.org/10.1016/j.infbeh.2003.06.001

Goldfield, E. C., Kay, B. A., \& Warren, W. H. (1993). Infant bouncing: the assembly and tuning of action systems. Child Development, 64(4), 1128-1142.

Habib Perez, O., Walters-Stewart, C., MineaultGuitard, A., Robertson, D. G. E., Baddour, N., \& Sveistrup, H. (2010). Infant bouncing during spring frequency perturbations. (pp. 14-15). Apresentado na Canadian Society for Psychomotor Learning and Sports Psychology (SCAPPS) Conference, Ottawa.

Heriza, C. B. (1991). Implications of a dynamical systems approach to understanding infant kicking behavior. Physical Therapy, 71(3), 222-235.

Jeka, J. J., \& Kelso, J. A. (1995). Manipulating symmetry in the coordination dynamics of human movement. Journal of Experimental Psychology. Human Perception and Performance, 21(2), 360-374. http://doi.org/10.1037/00961523.21.2.360

Jensen, J. L., Schneider, K., Ulrich, B. D., Zernicke, R. F., \& Thelen, E. (1994). Adaptive Dynamics of the Leg Movement Patterns of Human Infants: I. The Effects of Posture on Spontaneous Kicking. Journal of Motor Behavior, 26(4), 303-312.

http://doi.org/10.1080/00222895.1994.99416 86

Jensen, J. L., Thelen, E., Ulrich, B. D., Schneider, K., \& Zernicke, R. F. (1995). Adaptive Dynamics of the Leg Movement Patterns of Human Infants: III. Age-Related Differences in Limb Control. Journal of Motor Behavior, 27(4), 366-374.

http://doi.org/10.1080/00222895.1995.99417 24

Kay, B. A., Kelso, J. A., Saltzman, E. L., \& Schöner, G. (1987). Space-time behavior of single and bimanual rhythmical movements: data and limit cycle model. Journal of Experimental Psychology. Human Perception and Performance, 13(2), 178-192. http://doi.org/10.1037/00961523.13.2.178

Racic, V., \& Pavic, A. (2010). Mathematical model to generate near-periodic human jumping force signals. Mechanical Systems and Signal Processing, 24(1), 138-152. http://doi.org/10.1016/j.ymssp.2009.07.001

Sim, J., Blakeborough, A., Williams, M., \& Parkhouse, G. (2008). Statistical Model of Crowd Jumping Loads. Journal of Structural Engineering, 134(12), 1852-1861. http://doi.org/10.1061/(ASCE)07339445(2008) 134:12(1852)

Thelen, E. (1994). Three-month-old infants can learn task-specific patterns of interlimb coordination. Psychological Science, 5(5), 280-285. http://doi.org/10.1111/j.14679280.1994.tb00626.x

Vallis, L. A. (1998). Infant bouncing: Analysis of skilled and less-skilled behaviour. (Master Thesis in Health Sciences, Human Development). University of Ottawa, Ottawa, Canada. Obtido http://www.ruor.uottawa.ca/handle/10393/86 83 
38 | O Habib Perez, C Walters-Stewart, DGE Robertson, N Baddour, H Sveistrup

Wing, A. M. (2002). Voluntary timing and brain function: an information processing approach. Brain and Cognition, 48(1), 7-30. http://doi.org/10.1006/brcg.2001.1301

Todo o conteúdo da revista Motricidade está licenciado sob a Creative Commons, exceto quando especificado em contrário e nos conteúdos retirados de outras fontes bibliográficas. 